Research

\title{
Determinants of use of solar energy as an alternative means of energy by small and medium enterprises in Lagos State, Nigeria
}

\author{
Sylvester Anani Anaba ${ }^{1}$. Olusanya Elisa Olubusoye ${ }^{2}$
}

Received: 18 March 2021 / Accepted: 11 May 2021

Published online: 23 June 2021

(c) The Author(s) 2021 OPEN

\begin{abstract}
Frequent power outages and general electricity problems from the national grid in Nigeria have significantly increased in the last 5 years, and these are part of the reasons why many Small and Medium Enterprises in Lagos State, Nigeria find it difficult to survive and some have already folded up. Consequently, some Small and Medium Enterprises have relocated to other places, whilst others have resorted to the use of some alternative means of energy as backup facilities (inclusive of generating sets, and solar energy) to reduce the negative effect of frequent power outages from the national grid. Based on the foregoing, the aim of the study is to investigate whether Small and Medium Enterprises in Lagos State, Nigeria have considered solar energy as an alternative means of energy, find out whether Small and Medium Enterprises in Lagos State, Nigeria prefer solar energy to electricity from the national grid, and to also identify the determinants of use of solar energy as an alternative means of energy by Small and Medium Enterprises in Lagos State, Nigeria. The study covered selected Small and Medium Enterprises in Lagos State, Nigeria and primary data were generated from direct distribution of questionnaires to six hundred (600) qualified Small and Medium Enterprises in Lagos State. Using Descriptive Statistics and Binary Logistic Regression Model to analyze data generated from the questionnaires, the study affirmed that general cost of electricity from the national grid, poor organizational processes and procedures of Electricity Distribution Companies as well as policy support for solar energy by the government were major determinants of use of solar energy as an alternative means of power by Small and Medium Enterprises in Lagos State, Nigeria. However, the findings from the study indicate that poor customer services of Electricity Distribution Companies, inadequate access to electricity facilities of Electricity Distribution Companies, and frequent power outages were not major determinants of use of solar energy as an alternative means of energy by Small and Medium Enterprises in Lagos State, Nigeria as at the time of the research. Consequently, this study recommends that Electricity Distribution Companies should improve their organizational processes and procedures. The study also recommends that cost of maintenance and replacement of major facilities like defective transformers should not be transferred to Small and Medium Enterprises (inclusive of other clients).
\end{abstract}

Keywords Binary logistic · Electricity distribution companies · National grid · Power outages · Qualified small and medium enterprises
Abbreviations
DisCos Electricity Distribution Companies
EEB Estimated Electricity Bills

Sylvester Anani Anaba, sylvesteranaba@yahoo.com; Olusanya Elisa Olubusoye, busoye2001@yahoo.com | ${ }^{1}$ Center for Petroleum, Energy Economics, and Law (CPEEL), University of Ibadan, Ibadan, Oyo, Nigeria. ${ }^{2}$ Laboratory for Interdisciplinary Statistical Analysis (UI-LISA), Department of Statistics, University of Ibadan, Ibadan, Oyo, Nigeria. 


$\begin{array}{ll}\text { GCE } & \text { General Cost of Electricity } \\ \text { IAE } & \text { Inadequate Access to Electricity Facilities } \\ \text { NBPI } & \text { Nigerian Biofuel Policy and Incentives } \\ \text { NEMP } & \text { National Energy Master Plan } \\ \text { NEP } & \text { National Energy Policy } \\ \text { NPO } & \text { Number of Power Outages } \\ \text { NREEEP } & \text { National Renewable Energy and Energy Efficiency } \\ \text { PSS } & \text { Policy Support for Solar Energy } \\ \text { RCS } & \text { Rating of Customer Services } \\ \text { REAP } & \text { Renewable Electricity Action Program } \\ \text { REMP } & \text { Renewable Energy Master Plan } \\ \text { REPG } & \text { Renewable Electricity Policy Guidelines } \\ \text { ROC } & \text { Receiver Operating Characteristic Curves } \\ \text { RPP } & \text { Rating of Processes and Procedures } \\ \text { SMEs } & \text { Small and Medium Enterprises } \\ \text { USE } & \text { Use of Solar Energy }\end{array}$

\section{Introduction}

Small and Medium Enterprises (SMEs) in Lagos State, Nigeria suffer from frequent power outages. For instance, in 1998, some firms lost an average of seven hundred and ninety-two (792) working hours as a result of power outages, supposing a nine-hour working day, this translates to almost eighty-eight (88) working days in the year. Similarly, in 2004, some firms experienced three hundred and sixteen (316) power outages. These power outages rose by $26 \%$ in 2005 , followed by an explosive 43\% upsurge between 2006 and 2007. In the same vein, in 2017, SMEs suffered an average of forty-nine hours, twenty-five minutes of power outages totaling one hundred and ninety-seven (197) hours each month and summing up to two thousand, three hundred and sixty-four $(2,364)$ hours a year. Also, in year 2019, SMEs experienced power outages of about thirty-three (33) times in a month and this accumulates to three hundred and ninety-six (396) times in the year. The average monthly duration of power outages in year 2019 was about twelve (12) hours, and this amounted to about one hundred and forty-four (144) hours average duration of power outages in the year [1-5].

Due to frequent power outages, SMEs in Lagos State, Nigeria are unable to operate at an optimal capacity level as lack of power supply impedes and hinders their growth and operational performances. Accordingly, these SMEs report huge losses at the end of the year, partly as a result of frequent power outages from the national grid. In terms of competition, these SMEs are unable to compete globally as frequent power outages hinder them from operating at their full capacities. Averagely, SMEs lost circa $15.6 \%$ of their annual turnover (sales) to frequent power outages. Based on the foregoing, one (1) out of every seven (7) SMEs have left the economy, and some of the SMEs in Lagos State, Nigeria have shut down their businesses, whereas others have relocated to other places with relative stable supply of electricity [2, 3, 5-8].

To reduce the negative effect of frequent power outages on SMEs in Lagos State, Nigeria, some of the SMEs have invested a substantial percentage of their capital in alternative sources of energy (solar energy, geothermal, wind energy, biomass, power generating sets and other dirty fuels etc.). For instance, some SMEs generated about $56 \%$ of their electricity using power generating sets [5]. Amongst all these alternatives, renewable energy option has been adjudged as the most vibrant option. These alternative sources of energy complement and serve as backup facilities to the insufficient electricity supply from the national grid. Some SMEs incur extra cost whilst minimizing the effect of frequent power outages on their businesses. For instance, in year 2019, SMEs spent an average of Twenty thousand, One Hundred and Seventy-Nine Dollars $(\$ 20,179)^{1}$ in generating their own electricity [5]. In year 2020 , SMEs spent $21 \%$ of their revenue in generating their own electricity [8]. The average costs of some of these backup facilities are quite high as energy consumption constitutes over $40 \%$ of the operating cost of SMEs in Nigeria. In some instances, these backup facilities cost three times above the publicly supplied electricity from the national grid. The purchase and maintenance of these backup facilities therefore constitute an extra financial burden on SMEs on a continuous basis [3, 9-12].

${ }^{1}$ Using exchange rate of 380 Nigerian Naira to one Dollar. 
Further to the above problem faced by SMEs in Lagos State, Nigeria, some Researchers have indicated that SMEs need electricity for their businesses to grow and be profitable $[10,11,13]$. Based on the foregoing, other studies identified solar energy as an alternative source of energy and also, as a panacea to the frequent power outages faced by SMEs [14-16]. It is also believed that the frequent power outages faced by SMEs in Lagos, Nigeria will be resolved if SMEs accept and use renewable energy [12]. Further to the above, the Researchers were motivated to ask three research questions. These questions include, whether SMEs in Lagos State, Nigeria have considered solar energy as an alternative means of energy? Whether SMEs in Lagos State, Nigeria prefer solar energy to electricity from the national grid? What are the determinants of use of solar energy as an alternative means of energy by SMEs in Lagos State, Nigeria? Based on the above research questions, the objective of this paper is centered on investigating whether SMEs in Lagos State, Nigeria have considered solar energy as an alternative means of energy, find out whether SMEs in Lagos State, Nigeria prefer solar energy to electricity from the national grid, and to also identify the determinants of use of solar energy as an alternative means of energy by SMEs in Lagos State, Nigeria.

Based on the foregoing, this study is relevant and unique as it seeks to bridge the gap identified in reviewed literatures. For instance, there are several studies on SMEs with respect to energy issues. For ease of review and analysis, this study has classified extant literatures on SMEs and energy into two (2) categories. The first category of literatures concentrated on power outages, and the effects of power outages on the operations and profitability of SMEs $[2,3,6,10,13,15,17-19]$. The review of these set of literatures shows that most of the Researchers under this category have agreed that SMEs suffer from frequent power outages. Also, most studies under this category have shown that frequent power outages affect the operational and financial performances of SMEs. Similarly, the second category of literatures concentrated on renewable energy and other alternative sources of energy. The review of these set of literatures shows that most of the Researchers under the second category of literatures tested the level of acceptance of renewable energy, level of utilization of renewable energy, and factors influencing the acceptance of renewable energy [4, 16, 20-23]. Consequently, Researchers under the second category of literatures recommended renewable energy as a panacea to energy problem. However, these literatures have not find out if SMEs prefer solar energy to electricity from the national grid. Also, the review of literatures under the second category indicates that extant literatures have not identified the determinants of use of solar energy as an alternative means of energy to electricity from the national grid in Nigeria. Based on the foregoing, this study seeks to bridge the gap identified in the reviewed literatures by investigating whether SMEs in Lagos State, Nigeria have considered solar energy as an alternative means of energy, find out whether SMEs in Lagos State, Nigeria prefer solar energy to electricity from the national grid, and to also identify the determinants of use of solar energy as an alternative means of energy.

By the same token, the Researchers observed that most of the extant literatures used methodologies like Multiple Regression Techniques, Descriptive Statistics, Chi-Square, Ordinary Least Square Regression Techniques to analyze the effect of power outages, power fluctuation, and electricity insecurity on the performance of SMEs. Nevertheless, this study is unique and novel as it uses Descriptive Techniques and Binary Logistic Technique to identify the determinants of use of solar energy as an alternative to electricity from the national grid.

This study is also justified by its' economic relevance, and this can be discussed in two main perspectives. First, the results from this study will help both local and foreign investors in solar energy to know if there is acceptability and usage of solar energy amongst SMEs in Lagos State, Nigeria, and also help investors to know whether SMEs in Lagos State, Nigeria prefer solar energy to electricity from the national grid. Secondly, this study will help the Electricity Distribution Companies (DisCos) to understand the factors that attract SMEs to use solar energy instead of electricity from the national grid.

Consequently, the scope of the study is strictly limited to solar energy and electricity from the national grid with respect to SMEs in Lagos State, Nigeria. Hence, the study has no concern with the use of solar energy and electricity from the national grid by households and other businesses. In the same vein, other states in Nigeria, and other countries were not included in the study, thus, the study was strictly restricted to Lagos State, Nigeria.

Lagos State, Nigeria (the state, or Lagos) is surrounded on the east and north by Ogun State. The state shares boundaries with Republic of Benin in the west, and at the back of the southern boundary of the state is the Atlantic Ocean. Approximately, 22\% of Lagos State's 3577 km square are creeks and lagoons. The state was formed on 27 May 1967 in accordance to the State Creation and Transitional Provisions Decree Number 14 of 1967 which reorganized Nigeria into a 12 states federation. Lagos served the twin role of a federal capital and a state capital up until 1976, when the state capital was moved to Ikeja and the Federal Government's seat officially relocated to Abuja on 12 December 1991. Lagos State is divided into five (5) administrative divisions, which are further subdivided into thirty-seven (37) Local Government Areas. In 2003, the Local Government Areas were further divided into fifty-six (56) Local Council Development Areas for 
administrative reasons. The population figure of Lagos State as at 2017 was estimated at twenty-four million, fifty-one thousand, seven hundred and sixty-two $(24,051,762)$ persons [24].

Lagos is the main economic center of Nigeria, generating circa $10 \%$ of Nigeria's Gross Domestic Product. The state has the highest number of businesses in Nigeria with Small and Medium Enterprises (SMEs) accounting for eleven million, six hundred and sixty-three thousand $(11,663,000)$ businesses indicating $16.01 \%$ of the total number of businesses in Nigeria. As a result of the presence of most of the regulators and enforcement agencies as well as stiff competition amongst businesses in the state, SMEs in Lagos state are more proactive and efficient compared to other SMEs in other states in Nigeria. By definition, a small enterprise is a business with ten (10) to forty-nine (49) staff and has Thirteen Thousand, One Hundred and Fifty-Eight Dollars $(\$ 13,158)^{2}$ to One Hundred and Thirty-One Thousand, Five Hundred and Seventy-Nine Dollars $(\$ 131,579)$ of assets exclusive of land and buildings, whilst medium enterprise is a business with fifty $(50)$ to one hundred and ninety-nine (199) staff and has One Hundred and Thirty-One Thousand, Five Hundred and Seventy-Nine Dollars $(\$ 131,579)$ to less than One Million, Three Hundred and Fifteen Thousand, Seven Hundred and Eighty-Nine Dollars $(\$ 1,315,789)$ of assets exclusive of land and buildings $[25,26]$. Similarly, a small business is a business with eleven (11) to fifty $(50)$ workers, has not less than Thirteen Thousand, One Hundred and Fifty-Eight Dollars $(>\$ 13,158)$ to Two Hundred and Sixty-Three Thousand, One Hundred and Fifty-Eight Dollars $(\$ 263,158)$ of assets, and an annual turnover of Two Hundred and Sixty-Three Thousand, One Hundred and Fifty-Eight Dollars $(\$ 263,158)$. On the other hand, a medium business is a firm with fifty-one (51) to two hundred staff, has not less than Two Hundred and Sixty-Three Thousand, One Hundred and Fifty-Eight Dollars ( $>\$ 263,158$ ) to One Million, Three Hundred and Fifteen Thousand, Seven Hundred and Eighty-Nine Dollars $(\$ 1,315,789)$ of assets, and annual turnover of One Million, Three Hundred and Fifteen Thousand, Seven Hundred and Eighty-Nine Dollars $(\$ 1,315,789)[25,27]$.

Following this introduction, the remaining sections of the study include section two (2) which states the methodology of the study, and covers data description, data collection, and model specification. Section three (3) presents the results emanating from the study, whereas section four (4) of this study is discussion of results, whilst section five (5) is conclusion based on findings from the study.

\section{Methodology}

This section discusses the methodology of the study. The objectives of the study are to investigate whether SMEs in Lagos State, Nigeria have considered solar energy as an alternative means of energy, find out whether SMEs in Lagos State, Nigeria prefer solar energy to electricity from the national grid, and to also identify the determinants of use of solar energy as an alternative means of energy by SMEs in Lagos State, Nigeria. To achieve the above objectives, primary data were generated from the direct distribution of questionnaires to qualified SMEs in Lagos State, Nigeria. In this research, qualified SMEs are those SMEs that are connected to electricity from the national grid and are using solar energy. Consequently, questionnaires were not distributed to SMEs that did not meet the criteria of using solar energy and being connected to electricity from the national grid. Nevertheless, the unqualified SMEs were asked if they have accepted solar energy, and if they are planning to use solar energy in the nearest future. It is expedient to note that, the unqualified SMEs were not counted amongst the six hundred SMEs (600) used for this study.

\subsection{Research design}

The study involved a mixed type of methods (descriptive research method and binary logistic method). The descriptive research design (descriptive technique) was used to show an exact profile and characterization of SMEs that participated in the study. The descriptive technique was used to show sector of operation of SMEs, average monthly turnover of SMEs, average monthly profit of SMEs, identification of solar energy as an alternative means of energy by SMEs, and SMEs' preference for solar energy. These data are described using simple tables, charts, graphs and percentages. On the other hand, the Binary Logistic Regression Model involves dichotomous reference variables whose likelihoods were conditioned upon the explanatory variables. Since there are two (2) choices ("yes" or "no"), the Binary Logistics method is used to find out the determinants of use of solar energy as an alternative means of energy by SMEs in Lagos State, Nigeria.

\footnotetext{
2 Using Central Bank of Nigeria's official exchange rate of N380/\$1.
} 


\subsection{Research population and sampling design}

The population for this study was made up of randomly selected qualified SMEs from the urban, semi-urban and rural areas of Lagos State, Nigeria. In terms of sector of operation, the study used thirty-five (35) SMEs in agriculture, seventytwo (72) SMEs in education, seventy-four (74) SMEs in entertainment, seventeen (17) SMEs in finance, fifty (50) SMEs in health, sixty-seven (67) SMEs in hospitality, fifty-one (51) SMEs in manufacturing, one hundred and fifty-seven (157) SMEs in merchandize, forty-five (45) SMEs in transport and nine (9) SMEs in other sectors of the economy. A total of six hundred (600) qualified SMEs responded to the questionnaires, but twenty-three (23) respondents were rejected (as the respondents did not provide complete answers), and five hundred and seventy-seven (577) respondents were accepted for the study. Out of the accepted SMEs, four hundred and forty (440) SMEs were owned by male entrepreneurs, whilst one hundred and thirty-seven SMEs were owned by female entrepreneurs.

\subsection{Research instruments and data collection}

The research instrument that was used for this study was a structured questionnaire. Data for the study were collected through personal administration of questionnaires directly to six hundred (600) qualified SMEs randomly selected in Lagos State. The questionnaires were divided into two sections. The first section of the questionnaire was the introduction of the Researcher to the respondent(s) as well as a request to the respondent(s) to truly respond to the questions without bias. The first part of the questionnaire also assured the respondents that their responses will strictly be for research purposes and will be treated with utmost confidentiality.

The second section of the questionnaire is made up of three (3) sub-sections. Sub-section one (1) focused on questions that deal with personal characterization of the business owners. This section is centered on questions that cover specific attributes of the business owners and some key features of the SMEs that participated in the study. Sub-section two (2) asked questions that seek to find out the determinants of use of solar energy as an alternative to electricity from the national grid, whilst sub-section three (3) asked questions that attempt to test if SMEs prefer solar energy to electricity from the national grid.

Generally, the questions that were used for this research were closed-ended and binary questions. The closed-ended questions have options "A to $\mathrm{D}$ " and required respondents to choose the most objective answer amongst the available options. On the other hand, the binary questions required respondents to provide a "Yes or No" response. The binary questions were structured in a way that will enable the Researchers to analyze the primary data using the Binary Logistic Regression Techniques.

\subsection{Data description}

The study is made up of seven (7) explanatory variables, and these variables are briefly described below:

- General Cost of Electricity (GCE): This explanatory variable is the general cost of an SME being connected to electricity from the national grid. In this study, the general cost of an SME being connected to electricity from the national grid include cost of replacement of spoilt transformers apportioned to each SME in affected locations, cost of replacement of fallen electricity poles attributable to each SME in affected areas, cost of replacement of burnt wires, cost of hiring of ladders to reconnect SMEs back to the national grid electricity, and reconnection fees charged by DisCos when reconnecting SMEs back to the national grid electricity.

- Average Number of Power Outages (NPO): This variable is the estimated average number of times SMEs experience power outages from the national grid per week. Considering the fact that some SMEs may not be able to keep records of the exact number of times they experienced power outages in a week, the SMEs were asked to indicate an estimated average number of times of power outages in a week. Hence, this variable is an estimate based on SMEs' calculation of number of times they experienced power outages in a week.

- Average Rating of Customer Services of Electricity Distribution Companies (RCS): This variable is the rating of customers services of Distribution Companies (DisCos) by SMEs who participated in the research. In this study, customer services include the indirect and direct dealings, interfaces, interactions and communications of DisCos staff with customers. It also involves how customers are being handled and treated by DisCos staff. To get this rating, SMEs were asked to 
state their observations, opinions, thoughts and perception of DisCos's customer services in a scale of 1-10 (1 being the lowest and 10 being the highest rating).

- Average Rating of Processes and Procedures (RPP): This variable rates the organizational processes and procedures of DisCos by considering the number of hours it took DisCos to attend to and to resolve customers' complaints and inquiries. This variable also includes the number of processes that a customer has to pass through before his/her complaint will be resolved. SMEs who participated in this study were asked to indicate the estimated number of hours they spent before their complaints were resolved.

- Average Estimated Electricity Bills (EEB): This variable is estimated electricity bills. Most SMEs in Lagos State receive estimated electricity bills every month. This variable emanates from the fact that many SMEs did not have access to prepaid meters even when they are willing and able to acquire one for their business. Hence, estimated bills are sent to these SMEs at the end of every month. In most cases, these SMEs were over charged as estimated bills do not reflect the exact cost of electricity consumed by the SMEs in a month. Thus, SMEs that participated in this study were asked to give average monthly cost of their estimated electricity bills in a month.

- Inadequate Access to Electricity Facilities (IAE): Some SMEs in Lagos operate in areas where there are no electricity poles, wires, transformers and other facilities, and this could be due to poor road network to such areas. In some places, some of the facilities are obsolete and need replacement, but they have not been replaced. Hence, SMEs operating in such areas will have to contribute to acquire such facilities in order to have access to electricity from the national grid. Similarly, some SMEs did not have access to prepared meters and other accessories, these SMEs are forced to pay unrealistic amounts at the end of every month as electricity bills. Consequently, SMEs that participated in this study were asked to state the average number of times that they experienced inadequate access to electricity facilities has informed their use of solar energy.

- Policy Support for Solar Energy (PSS): This variable is policy support for solar energy. Having considered the frequent power outages in the country, and the continuous folding up of businesses as a result of power outages, the government has considered several alternative means of energy, inclusive of renewable energy. Thus, the government has formulated several policies in support of renewable energy. Some of these policies include, National Energy Policy (NEP) April 2003, Renewable Energy Master Plan (REMP) November 2005, Renewable Electricity Policy Guidelines (REPG) December 2006, Renewable Electricity Action Program (REAP) 2006, Nigerian Biofuel Policy and Incentives (NBPI) 2007, National Energy Master Plan (NEMP) 2014, and National Renewable Energy and Energy Efficiency Policy (NREEEP) 2015. As a result of these policies, some solar energy projects in the country have been bolstered and supported by some individuals and institutions. SMEs that participated in the study were asked to rate how much influence government policies on renewable energy has on their decision to use solar energy.

\subsection{Model specification}

Given the use of solar energy as an alternative to electricity from the national grid (USE), and the determinants of use of solar energy as GCE, NPO, RCS, RPP, EEB, IAE and PSS, the functional relationship was specified as:

$$
U S E=f(G C E, N P O, R C S, R B P, E E B, I A E, P S S)
$$

[28].

Table 1 above gives the definition and description of variables used in the model. Table 1 also describes whether varaibles are quantitative or qualitative. The linear function of the model was specified as:

$$
U S E=\beta 0+\beta_{1} G C E+\beta_{2} N P O+\beta_{3} R C S+\beta_{4} R B P+\beta_{5} E E B+\beta_{6} I A E+\beta_{7} P S S+\varepsilon_{t}
$$

[28].

The a priori expectations of the explanatory variables in the above Models are summarized in Table 2 below:

The fitted or expected value of the Binary Logistic Model is based on the link function, $\log P /(1-P)$. In order to establish a linear relationship of the expected value, $P$, and the linear predictor, we have the following relationships:

$$
\operatorname{In} \frac{\left(P_{1}\right)}{\left(1-P_{1}\right)}=U S E=\beta 0+\beta_{1} G C E+\beta_{2} N P O+\beta_{3} R C S+\beta_{4} R B P+\beta_{5} E E B+\beta_{6} I A E+\beta_{7} P S S+\varepsilon_{t}
$$

[28]. 


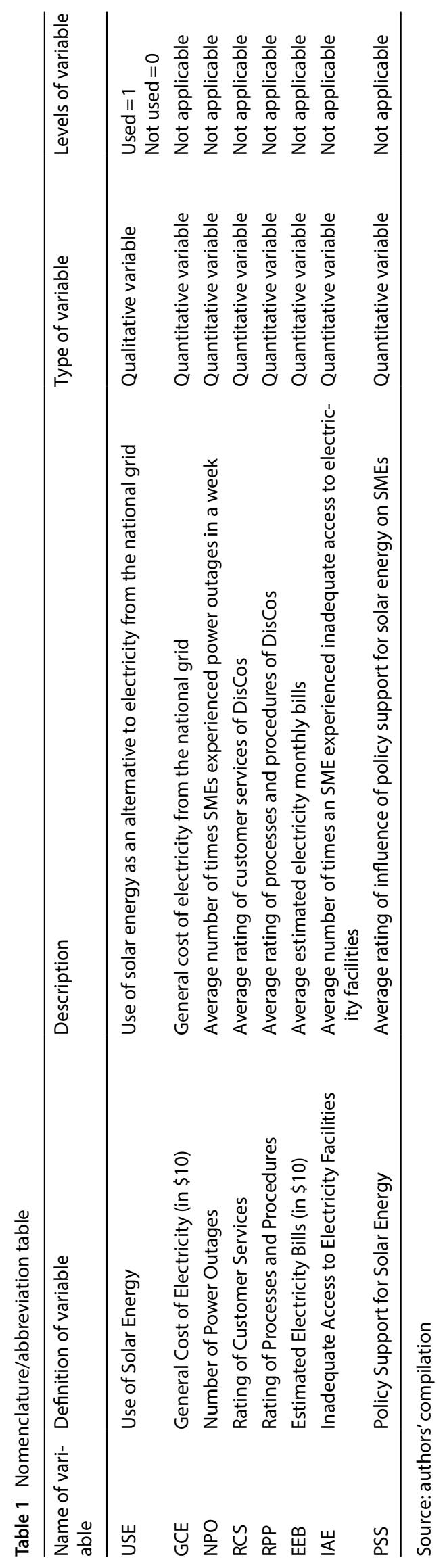


Table 2 A priori expectation of the explanatory variables

\begin{tabular}{llll}
\hline Response variable & Predictor variables & $\begin{array}{l}\text { Expected } \\
\text { signs }\end{array}$ \\
\hline USE = Use of solar energy & GCE & General cost of electricity & + \\
& NPO & Average number of power outages & + \\
RCS & Average rating of customers services of DisCos & + \\
RPP & Average rating of processes and procedures of DisCos & + \\
& EEB & Average estimated electricity bills & + \\
& IAE & Inadequate access to electricity facilities & + \\
& PSS & Policy support for solar energy & + \\
\hline
\end{tabular}

Source: researchers' compilation

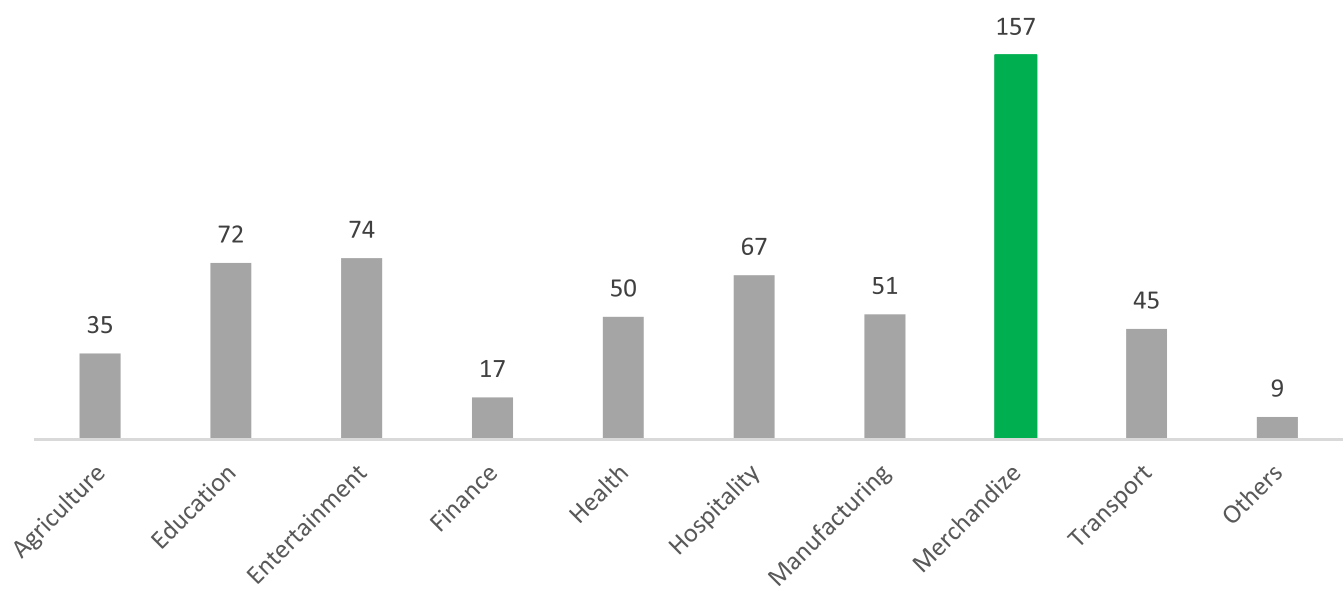

Fig. 1 Number of Participating SMEs in each Sector. Source: Researchers' Questionnaires

Where $P$ is the probability that the response value dependent value (USE) is equal to 1 . It can also be seen as the probability of the existence or occurrence of some characteristic, while 1-P can be seen as the probability of the absence of some characteristic.

Since we have multiple predictors, the equation for the prediction of the probability will be as follows:

$$
P=\frac{\boldsymbol{e} \beta 0+\beta_{1} G C E+\beta_{2} N P O+\ldots+\beta_{7} P S S}{1+\boldsymbol{e} \beta 0+\beta_{1} G C E+\beta_{2} N P O+\ldots+\beta_{7} P S S}=\frac{1}{1+\boldsymbol{e} \beta 0+\beta_{1} G C E+\beta_{2} N P O+\ldots+\beta_{7} P S S}
$$

[28].

\section{Results}

The overall objective of this study is to find out the determinants of use of solar energy as an alternative means of energy to electricity from the national grid. To achieve the above objective, primary data generated from the direct administration of questionnaires to six hundred (600) SMEs in Lagos State were analyzed and, some of the major results generated from the analysis of the data using Descriptive Techniques and Binary Logistics Techniques are presented thus:

Figure 1 above signifies that SMEs in Merchandize had the highest participation in the survey with one hundred and fifty-seven (157), followed by those in Entertainment (74), Education (72), Hospitality (67), Manufacturing (51), Health (50), Transport (45), Agriculture (35), Finance (17), and Others (9).

Considering estimated monthly turnover, Fig. 2 above indicates that majority of the SMEs had an estimated monthly turnover of about Seven Hundred and Ninety Dollars $(\$ 790)$ and above.

Looking at estimated monthly profits, Fig. 3 above implies that about two hundred and twenty-one SMEs of the population had an estimated monthly profit of over Five Hundred and Twenty-Six Dollars ( $>\$ 526)$. 
Fig. 2 Estimated Monthly Turnover of Respondent SMEs. Source: Researchers' Questionnaires

Fig. 3 Estimated Monthly Profit of Respondents' Profit. Source: Researchers' Questionnaires
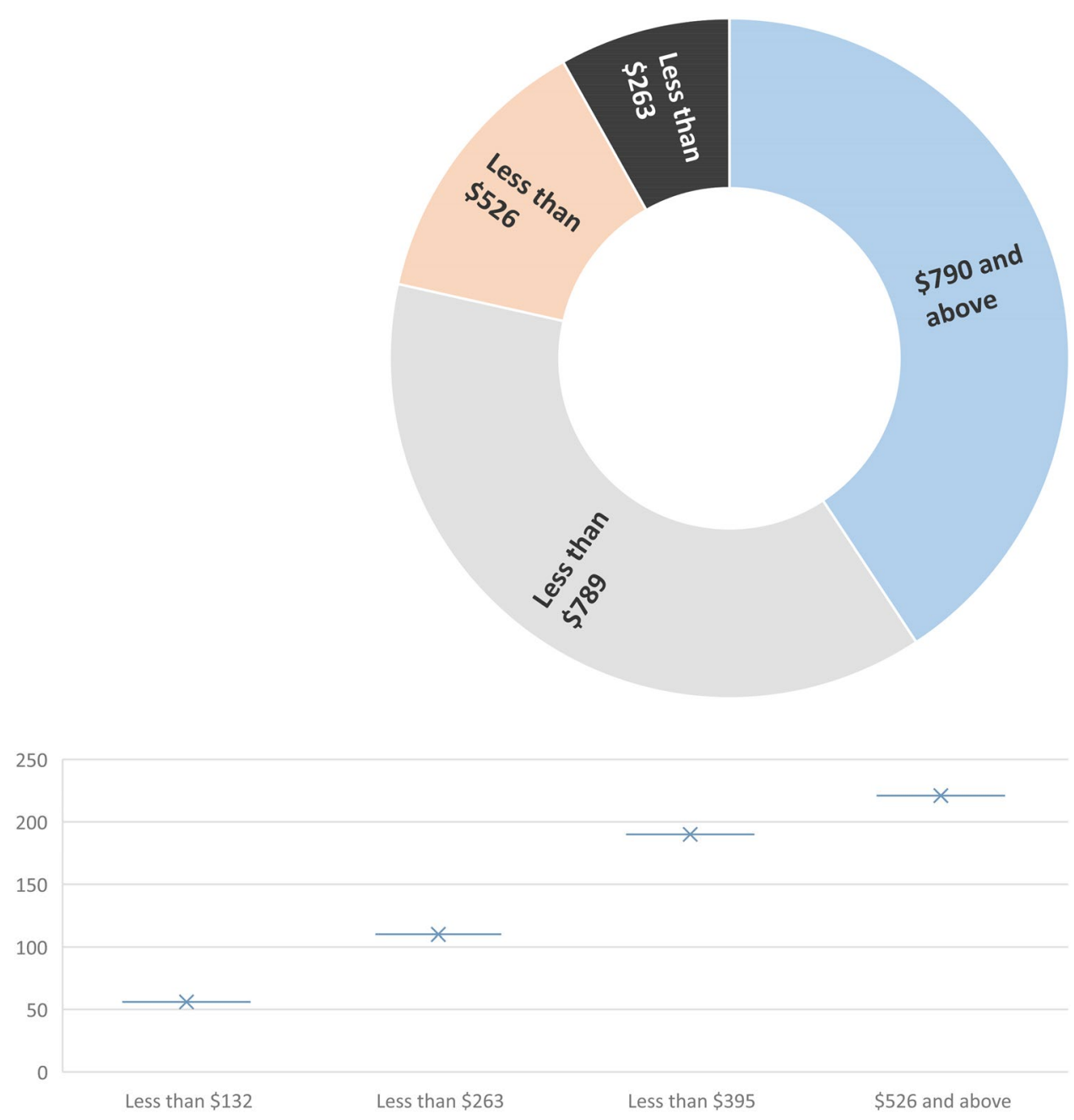

Fig. 4 Solar Energy as an Alternative Means of Energy to Electricity from the National Grid. Source: Researchers Questionnaires

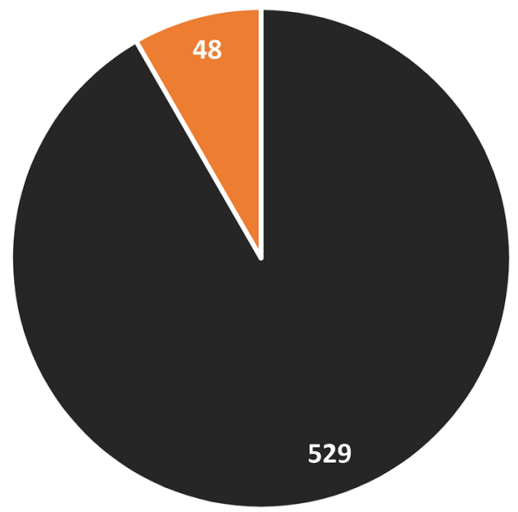

- Solar is alternative to PHCN

Figure 4 above shows that five hundred and twenty-nine (529) SMEs representing 92\% of the population identified solar energy as an alternative means of energy to electricity from the national grid. Conversely forty-eight (48) SMEs representing $8 \%$ of the population did not identify solar energy as an alternative to electricity from the national grid.

Table 3 above shows that a large number of SMEs in Lagos State have identified solar energy as an alternative to electricity from the national grid with $91 \%, 93 \%$ and $85 \%$ across the urban, semi-urban and rural areas of Lagos State respectively. 
Table 3 Cross tabulation of solar energy as an alternative to electricity from the national grid

\begin{tabular}{|c|c|c|c|}
\hline Locations & Options & Frequency & Percentage \\
\hline \multirow[t]{3}{*}{ Urban } & Solar energy is an alternative means of energy to electricity from the national grid & 349 & $91 \%$ \\
\hline & Solar energy is not an alternative means of energy to electricity from the national grid & 33 & $9 \%$ \\
\hline & Total & 382 & 100 \\
\hline \multirow[t]{3}{*}{ Semi-urban } & Solar energy is an alternative means of energy to electricity from the national grid & 151 & $93 \%$ \\
\hline & Solar energy is not an alternative means of energy to electricity from the national grid & 11 & $7 \%$ \\
\hline & Total & 162 & 100 \\
\hline \multirow[t]{3}{*}{ Rural } & Solar energy is an alternative means of energy to electricity from the national grid & 28 & $85 \%$ \\
\hline & Solar energy is not an alternative means of energy to electricity from the national grid & 5 & $15 \%$ \\
\hline & Total & 33 & 100 \\
\hline
\end{tabular}

Source: researchers' questionnaire

Acceptance and Use of Solar Energy, 70\%

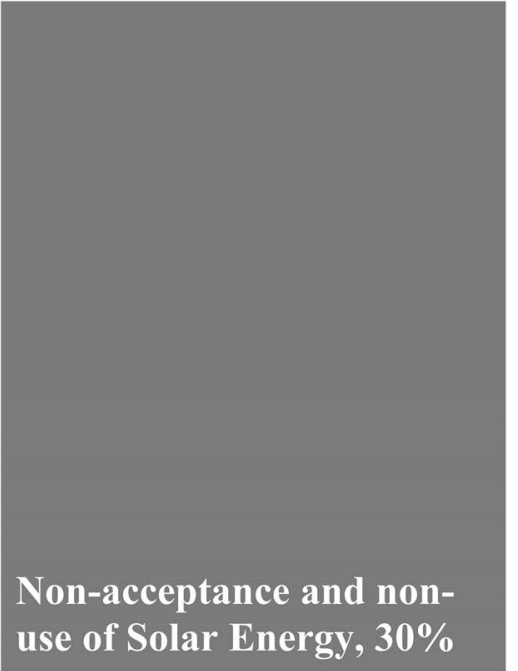

Fig. 5 Acceptance and Use of Solar Energy amongst SMEs in Lagos State, Nigeria. Source: Researchers' Questionnaires

Figure 5 above shows that $70 \%$ of SMEs in Lagos State, Nigeria have accepted and agreed to use solar energy as at the time of this study. However, $30 \%$ of the SMEs in Lagos State, Nigeria are yet to accept and use solar energy.

Figure 6 above shows that four hundred and eighty-nine (489) SMEs representing $85 \%$ of the entire population preferred solar energy to electricity from the national grid, whilst eighty-eight (88) SMEs representing 15\% of the entire population did not prefer solar energy to electricity from the national grid.

Table 4 above shows that out of five hundred and seventy-seven (577) SMEs, four hundred and eighty-nine (489) SMEs (representing $85 \%$ of the total population) preferred solar energy, whilst eighty-eight SMEs (representing $15 \%$ of the total population) did not prefer solar energy to electricity from the national grid.

Generally, in Fig. 7 above, SMEs in the merchandize space showed highest preference for solar energy (29\%), followed by SMEs in the education and entertainment sectors (12\% respectively), whilst SMEs in the hospitality sector followed with $11 \%$, those in the health sector with $9 \%$, manufacturing recorded $8 \%$, whereas SMEs in the transportation sector had 7\%, SMEs in Agriculture sector had 6\%, but SMEs in the Finance Sector and those in other sectors recorded the lowest preference of $3 \%$ and $1 \%$ respectively.

Table 5 above shows the mean, median, variance, standard deviation, skewness, and kurtosis etc. of the variables used for the study.

Table 6 above contains odds ratios, coefficients, standard errors, z-statistic, p-values, and the $95 \%$ confidence intervals of the coefficients. The $95 \%$ confidence interval shows the confidence level for the coefficients. The confidence intervals are related to the $p$-values such that the coefficients will not be statistically significant if the confidence interval includes zero (0). The log likelihood of -152.30105 indicates that the model fits well. 
Fig. 6 Preference for Solar Energy by SMEs. Source:

Researchers' Questionnaires

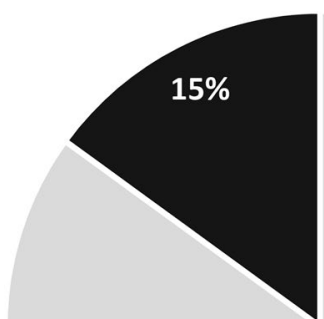

$85 \%$

Preferred solar energy

- Did not prefer solar energy

\begin{tabular}{|c|c|c|c|c|c|}
\hline & No. of SME & Preferred solar & $\begin{array}{l}\text { Did not } \\
\text { Prefer Sola }\end{array}$ & $\begin{array}{l}\text { Preferred } \\
\text { solar (\%) }\end{array}$ & $\begin{array}{l}\text { Did not pre- } \\
\text { fer Solar (\%) }\end{array}$ \\
\hline
\end{tabular}

General

preference

(\%)

\begin{tabular}{lrrrrrr}
\hline Agriculture & 35 & 29 & 6 & 83 & 17 & 6 \\
Education & 72 & 61 & 11 & 85 & 15 & 12 \\
Entertainment & 74 & 61 & 13 & 82 & 18 & 12 \\
Finance & 17 & 15 & 2 & 88 & 12 & 3 \\
Health & 50 & 44 & 6 & 88 & 12 & 9 \\
Hospitality & 67 & 55 & 12 & 82 & 18 & 11 \\
Manufacturing & 51 & 40 & 11 & 78 & 22 & 8 \\
Merchandize & 157 & 141 & 16 & 90 & 10 & 29 \\
Transportation & 45 & 36 & 9 & 80 & 20 & 7 \\
Others & 9 & 7 & 2 & 78 & 22 & 1 \\
Total & 577 & 489 & 88 & 85 & 15 & 100 \\
\hline
\end{tabular}

Source: researchers questionnaires

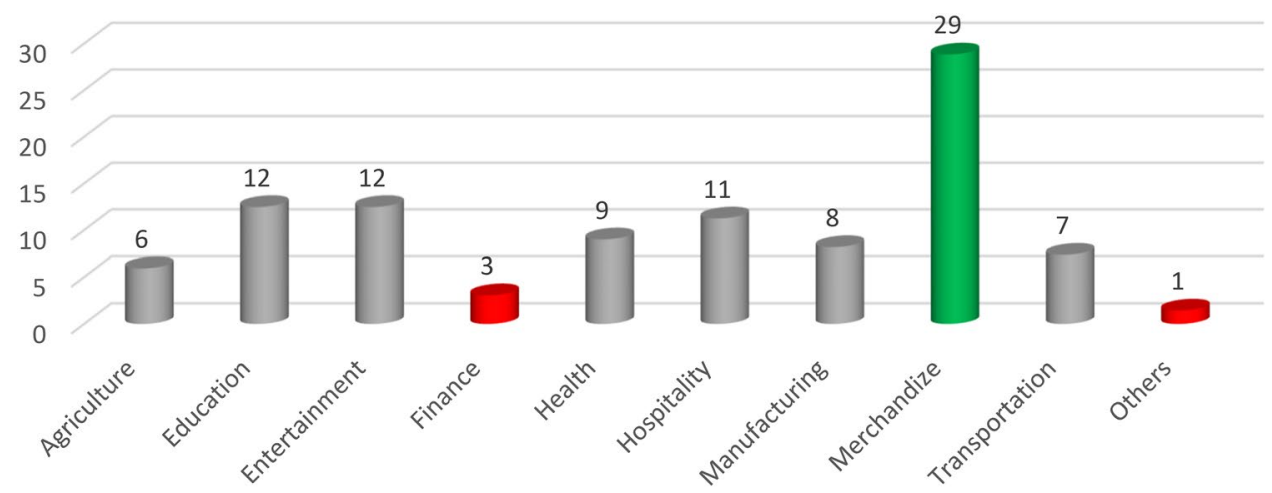

Fig. 7 General Analysis of SMEs' Preference for Solar Energy. Source: Researchers' Questionnaires

The Hosmer-Lemeshow statistic indicates a poor fit if the significance value is less than 0.05 . However, Table 7 above shows a Chi-Square of 5.700 and significance value of 0.681 closer to one (1). This indicates a good overall fit of the model.

Table 8 above is the contingency table for Hosmer and Lemeshow test showing the observed and expected observations for the dummy variables used in the study. 
Table 5 Summary of descriptive results

\begin{tabular}{llllllll}
\hline & GCE & NPO & RCS & RPP & EEB & IAE & PSS \\
\hline Mean & 7.473137 & 7.738302 & 4.814558 & 7.941075 & 6.807626 & 5.154246 & 6.454073 \\
Median & 8.000000 & 8.000000 & 4.000000 & 9.000000 & 6.000000 & 4.000000 & 6.000000 \\
Variance & 2.124711 & 3.391464 & 1.453399 & 5.795133 & 5.325775 & 1.672347 & 2.911516 \\
Std. Dev & 1.457639 & 1.841593 & 1.205570 & 2.407308 & 2.307764 & 1.293193 & 1.706316 \\
Skewness & -0.653760 & -0.376972 & 1.240024 & -0.819294 & 0.119820 & 0.830087 & 0.102654 \\
Kurtosis & 3.416905 & 1.910157 & 3.717309 & 2.331778 & 1.573779 & 3.319210 & 2.233731 \\
Jarque-Bera & 45.28050 & 42.22169 & 160.2418 & 75.28632 & 50.28392 & 68.71279 & 15.12989 \\
Probability & 0.000000 & 0.000000 & 0.000000 & 0.000000 & 0.000000 & 0.000000 & 0.000518 \\
Sum & 4312.000 & 4465.000 & 2778.000 & 4582.000 & 3928.000 & 2974.000 & 3724.000 \\
Sum Sq. Dev & 1223.834 & 1953.484 & 837.1577 & 3337.997 & 3067.646 & 963.2721 & 1677.033 \\
Observations & 577 & 577 & 577 & 577 & 577 & 577 & 577 \\
\hline
\end{tabular}

Source: researchers questionnaires

Table 6 Presentation of regression result

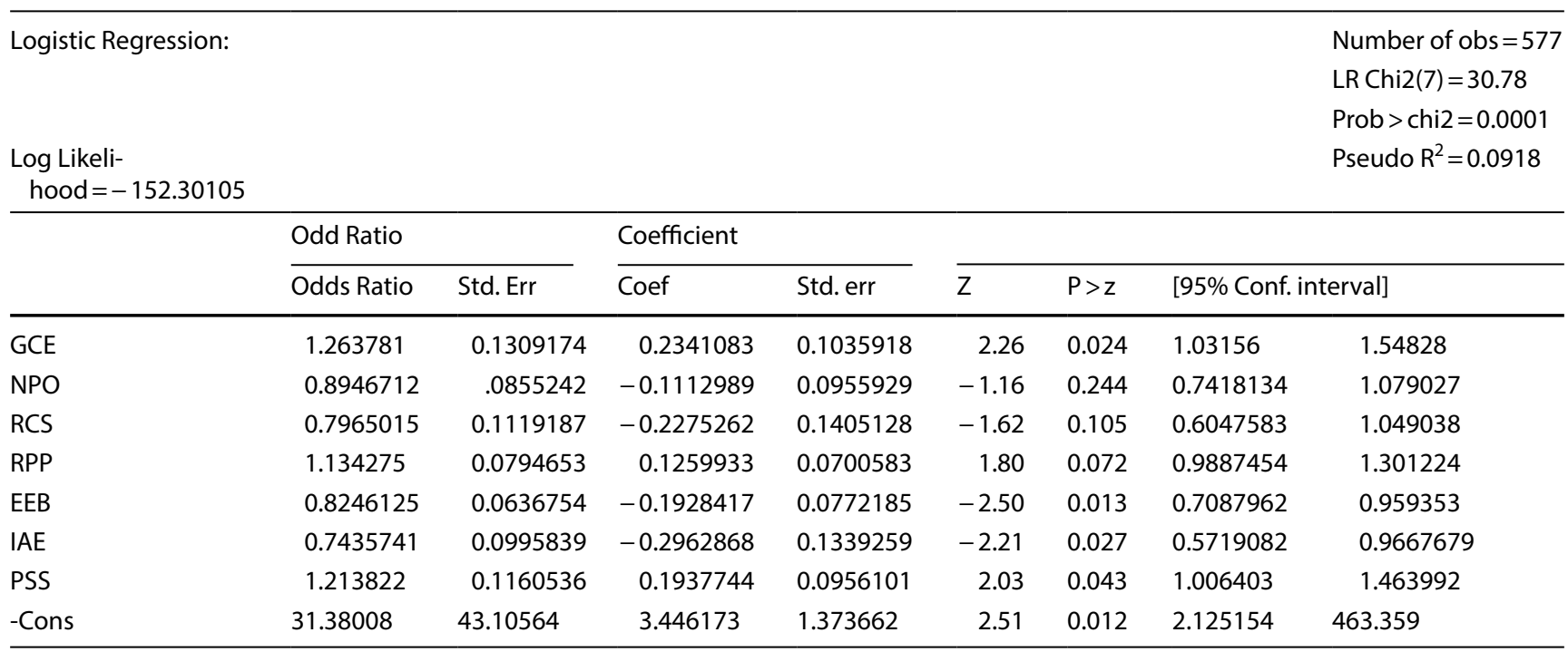

Source: researchers' questionnaires

Table 7 Hosmer-Lemeshow Test

\begin{tabular}{llll}
\hline Step & Chi-square & Dif & Sig. \\
\hline 1 & 5.700 & 8 & 0.681 \\
\hline Source: researchers' analysis & & &
\end{tabular}

Table 9 above gives the result of the likelihood ratio Chi-Square (LR chi2(7)) at 30.78 using a p-value of 0.0001 implies that the model as a whole fits significantly better than an empty model (i.e., a model with no predictors).

Table 10 gives the overall summary of the model, and it implies that the model was suitable for the research.

\subsection{Predictive accuracy of the model}

The predictive accuracy of the model was assessed using Classification Tables and Receiver Operating Characteristic Curves (ROC). The results are presented in Table 11 and Figs. 7, 8, 9, 10, 11, 12 below.

Table 11 above shows an overall percentage of $91.2 \%$ and this is above the $50 \%$ cut-off value. This indicates that all the predictors correctly predicted the dependent variable in the model. 
Table 8 Contingency table for Hosmer and Lemeshow Test

\begin{tabular}{|c|c|c|c|c|c|}
\hline & \multicolumn{2}{|l|}{$\mathrm{ASP}=0$} & \multicolumn{2}{|l|}{$\mathrm{ASP}=1$} & \multirow[t]{2}{*}{ Total } \\
\hline & Observed & Expected & Observed & Expected & \\
\hline Step 1 & 17 & 14.414 & 41 & 43.586 & 58 \\
\hline 2 & 8 & 8.337 & 49 & 48.663 & 57 \\
\hline 3 & 4 & 6.296 & 53 & 50.704 & 57 \\
\hline 4 & 4 & 4.901 & 54 & 53.099 & 58 \\
\hline 5 & 5 & 3.913 & 52 & 53.087 & 57 \\
\hline 6 & 3 & 3.290 & 55 & 54.710 & 58 \\
\hline 7 & 5 & 2.833 & 54 & 56.167 & 59 \\
\hline 8 & 1 & 2.235 & 57 & 55.765 & 58 \\
\hline 9 & 2 & 1.709 & 56 & 56.291 & 58 \\
\hline 10 & 0 & 1.071 & 57 & 55.929 & 57 \\
\hline
\end{tabular}

Source: researchers' analysis

Table 9 Omnibus tests of model coefficients

Table 10 Model summary

Table 11 Classification table

Fig. 8 ROC for GCE. Source: Researchers' Analysis

\begin{tabular}{lllll}
\hline & Chi-square & Df & Sig. \\
\hline Step 1 & Step & 30.784 & 7 & Less 0.001 \\
& Block & 30.784 & 7 & Less 0.001 \\
& Model & 30.784 & 7 & Less 0.001 \\
\hline
\end{tabular}

Source: researchers' analysis

\begin{tabular}{llll}
\hline Step & $-2 \log$ Likelihood & Cox and Snell R Square & Negelkerke R Square \\
\hline 1 & $304.602^{\mathrm{a}}$ & 0.52 & 0.118 \\
\hline
\end{tabular}

Source: researchers' analysis

${ }^{a}$ Estimation terminated at iteration number 6 because parameter estimates changed by less than 0.001

\begin{tabular}{llllr}
\hline Observed & ASP & Predicted & ASP & Percentage \\
\hline Step 1 & 0 & 0 & 49 & 0.0 \\
& 1 & 2 & 526 & 99.6 \\
Overall Percentage & & & & 91.2 \\
\hline
\end{tabular}

Source: researchers' analysis

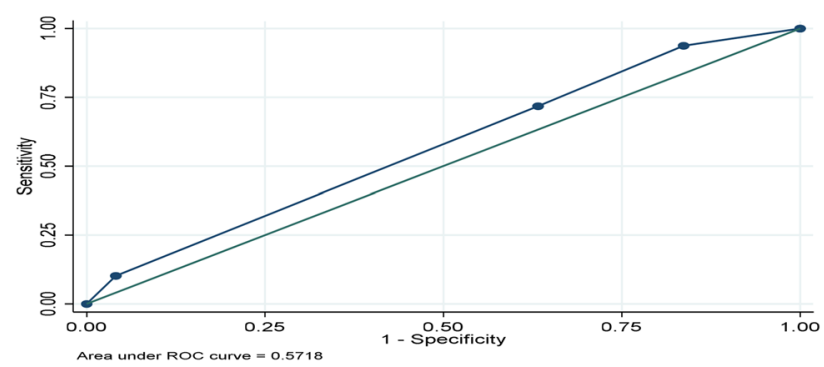


Fig. 9 ROC for NPO. Source: Researchers' Analysis

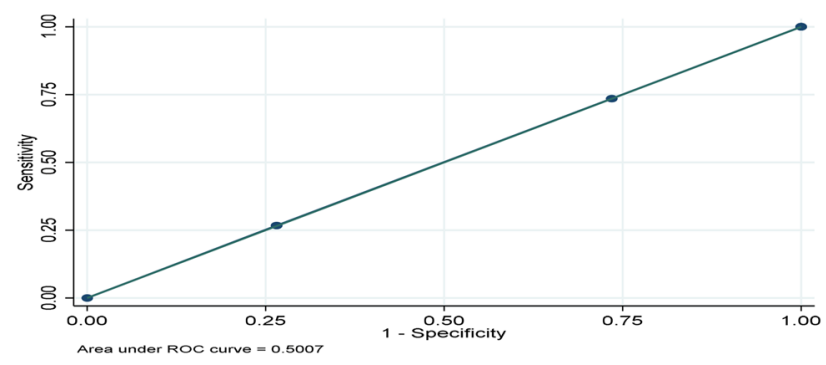

Fig. 10 ROC for RCS. Source: Researchers' Analysis

Fig. 11 ROC for RPP. Source: Researchers' Analysis

Fig. 12 ROC for IAE. Source: Researchers' Analysis

Fig. 13 ROC for PSS. Source: Researchers' Analysis
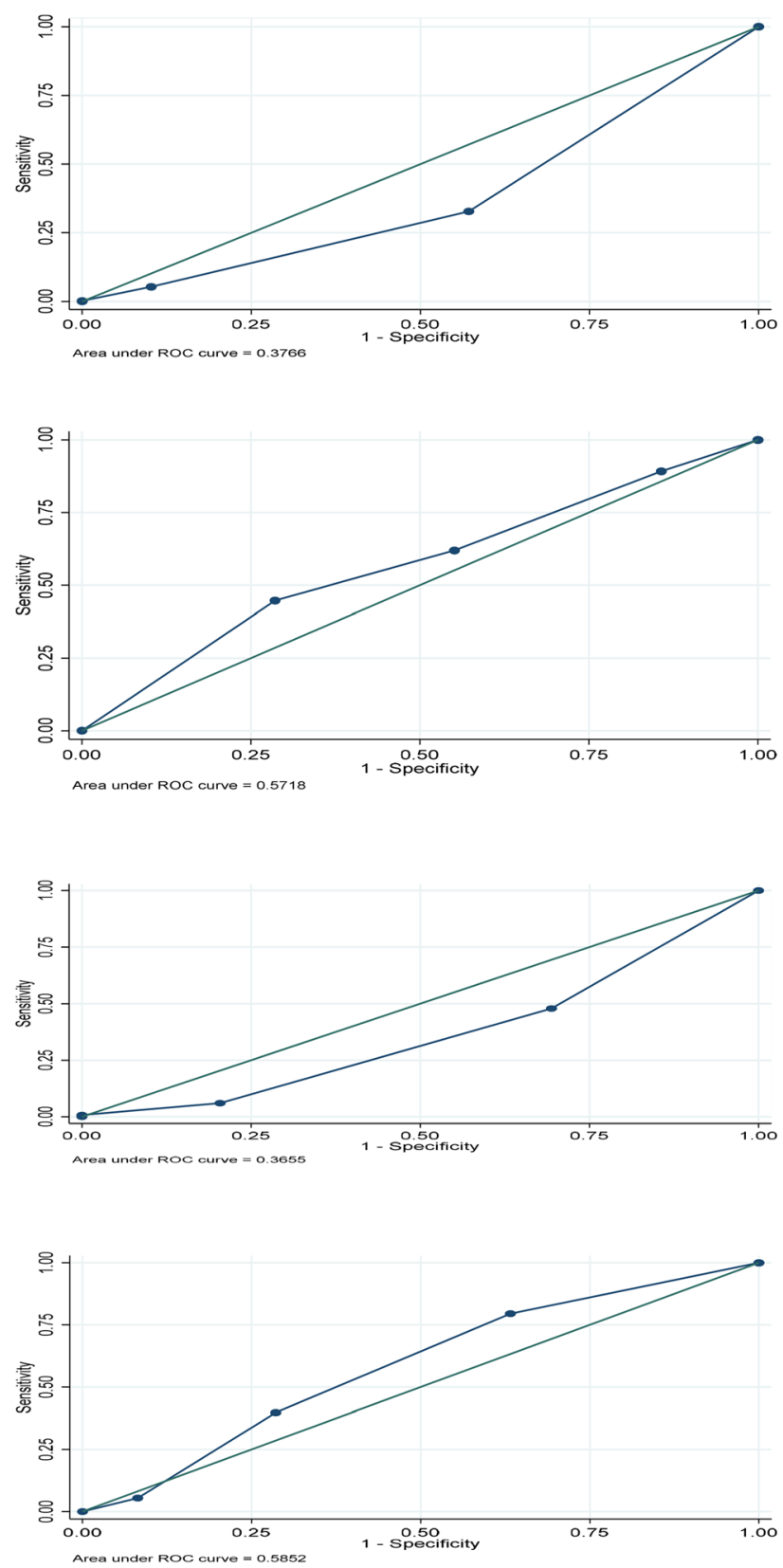
The Receiver Operating Characteristic Curves (ROC), Figs. 8, 9, 10, 11, 12, 13 above give more information relative to the Classification Table as it reflects the predictive power for all cut-off values regarding the variables used in this study.

Summarily, the major results shown in this section indicate that $92 \%$ of the SMEs that participated in the study identified solar energy as an alternative means of energy to electricity from the national grid, and $85 \%$ preferred solar energy to electricity from the national grid. Similarly, from the analysis of data obtained for this study, general cost of electricity, poor processes and procedures of DisCos, and policy support for solar energy were major determinants of use of solar energy as an alternative to electricity from the national grid in this study.

\section{Discussion}

This paper used Descriptive Techniques and Binary Logistic Techniques to analyze data obtained directly from the administration of questionnaires to six hundred (600) SMEs in Lagos State. Consequently, this sections contains discussions on the major results presented in the prior section.

The results shown in Fig. 4 above indicate that $92 \%$ of SMEs that participated in the study have considered and identified solar energy as an alternative means of energy. This implies that most SMEs in Lagos State, Nigeria are aware of solar energy as an alternative to electricity from the national grid. Similarly, the results found in Fig. 5 and Table 4 above show an acceptance and usage level of $70 \%$ amongst SMEs that participated in the study, and this indicates that many SMEs in Lagos State, Nigeria have accepted and used solar energy in Lagos State, Nigeria. Nevertheless, this result does not agree with Obafemi Olatunji's findings that posited that the acceptance level of solar energy in Nigeria is low [12]. Aside this, Fig. 6 shows that $85 \%$ of the SMEs that participated in the study prefer solar energy to electricity from the national grid as at the time of the study. By the same token, the results in Table 6 above show that the log-odds for general cost of electricity (GCE) from the national grid, poor procedures and processes (RPP) of DisCos, and policy support for solar energy (PSS) recorded positive values and this implies that:

- For every Ten Dollars (\$10) increase in general cost of electricity (GCE) from the national grid (holding all other predictors constant), the log-odds for solar energy as an alternative means of energy increases by 0.2341 . In this study this implies that GCE significantly increases the possibility of using solar energy as an alternative means of power by SMEs in Lagos State.

- For every one-hour increase in poor organizational practices and procedures (RPP) of DisCos (holding all other variables constant), the log-odds for solar as an alternative means of energy increases by 0.1260 . This signifies that, RPP expressively increases the probability of using solar energy as an alternative means of power by SMEs in Lagos State in this study.

- For every additional policy support for solar energy (PSS) from the government (holding all other variables constant), the log-odds for solar energy as an alternative means of energy increases by 0.1938 . This indicates that PSS significantly increases the chances of using solar energy as an alternative means of power by SMEs in Lagos State in this study. This particular result is similar to Yusuf Opeyemi's findings [16].

However, the log-odds for average number of power outages (NPO), average rating of customer services (RCS) of Dis$\mathrm{Cos}$, average estimated monthly electricity bills $(\mathrm{EEB})$, and average number of times customers experience inadequate access to electricity facilities (IAE) of DisCos showed negative log-odds. This implies that from the analysis of data used for this study, NPO, RCS, EEB and IAE less likely determined solar energy as an alternative source of power by SMEs in Lagos State in this study. In other words, we may say that an increase in NPO, RCS, EEB and IAE less likely lead to increase in the use of solar energy as an alternative source of power by SMEs in Lagos State in this research.

\section{Conclusion}

In this study, the Researchers have found out that many SMEs in Lagos State, Nigeria have considered solar energy as an alternative means of energy, discovered that most SMEs prefer solar energy to electricity from the national grid, and empirically find out that as at the time of this research, general cost of electricity from the national grid, poor organizational practices and procedures of DisCos, and policy support for solar energy from the government are major determinants of use of solar energy as an alternative means of energy by SMEs in Lagos State, Nigeria. However, from 
the analysis of data used in this study, average number of power outages, poor rating of customer services, average estimated monthly electricity bills, and average number of times customers experience inadequate access to electricity facilities of DisCos were not discovered as major determinants of use of solar energy as an alternative means of energy by SMEs in Lagos State, Nigeria as at the time of this study.

In a global context, this study has empirically shown foreign investors that $70 \%$ of SMEs in Lagos State, Nigeria have accepted and agreed to use solar energy. This indicates an investment opportunity for foreign investors that may want to invest on solar energy in Lagos State, Nigeria. By the same token, this research has identified some major factors that attract SMEs to use solar energy instead of electricity from the national grid. Practically, these factors may be used by foreign developers as a marketing tool in attracting SMEs in Lagos State, Nigeria in patronizing their solar energy products.

Based on the above findings, this study recommends that cost of repairs, maintenance, and replacement of major facilities like defective transformers should not be transferred to SMEs (and other clients), as this increases SME's general cost of being connected to electricity from the national grid. It is therefore expedient for DisCos to sponsor the repairs, maintenance and replacement of major electricity facilities like transformers. Similarly, the study encouraged DisCos to improve their organizational processes and procedures so as to attract, increase, and retain customers. To achieve this, DisCos must reduce the number of hours with which an SME (inclusive of other clients) spend before their complaints are being attended to. Consequently, DisCos must reduce their bureaucratic tapes (number of processes and procedures that customers have to go through) with respect to customers.

Authors' contributions The topic of the research was formulated by OEO. The entire paper was written by SAA. All authors read and approved the final manuscript.

Data availability The datasets generated during and/or analyzed during this study are not publicly available due to the request of some respondents not to share their data publicly without reasonable permission. Hence, data will be available from the corresponding author on reasonable request and respondents' permission.

\section{Declarations}

Competing interests The authors declares no competing interests.

Open Access This article is licensed under a Creative Commons Attribution 4.0 International License, which permits use, sharing, adaptation, distribution and reproduction in any medium or format, as long as you give appropriate credit to the original author(s) and the source, provide a link to the Creative Commons licence, and indicate if changes were made. The images or other third party material in this article are included in the article's Creative Commons licence, unless indicated otherwise in a credit line to the material. If material is not included in the article's Creative Commons licence and your intended use is not permitted by statutory regulation or exceeds the permitted use, you will need to obtain permission directly from the copyright holder. To view a copy of this licence, visit http://creativecommons.org/licenses/by/4.0/.

\section{References}

1. Adenikinju, A. Analysis of the Cost of Infrastructure Failures in a Developing Economy: the Case of the Electricity Sector in Nigeria. African Economic Research Consortium, Nairobi. AERC Research Paper 148; 2005.

2. Iwayemi A. Nigeria's dual energy problems: policy issues and challenges. International Association for Energy Economics; 2008.

3. Ado A, Mangai MJ. Impact of deficient electricity supply on the operations of small-scale businesses in North East Nigeria. Int J Business Econ Dev. 2015; 3(1).

4. Dalberg Global Development Advisors May 2017. Improving access to electricity through decentralized renewable energy, policy analysis from India, Nigeria, Senegal and Uganda. Extracted on Friday, 18 December 2020. https://sun-connect-news.org/fileadmin/DATEIEN/ Dateien/New/Dalberg-offgrid-policy.pdf.

5. Nwanakwere JT, Uzoeto J. Electrical Energy Insecurity and the Performance of the Small and Medium Enterprise Sub-Sector in Nigeria. AUDOE. 2019; 15(6): 55-69. ISSN: 2065-0175 OECONOMICA

6. Udochukwu BA, Ogbonnaya IO. Economic implications of constant power outages on SMEs in Nigeria. J Energy South Afr. $2014 ; 25(3): 61$.

7. Momoh Z, Joseph A, et al. Implications of poor electricity supply on nigeria's national development. Humanities and Social Sciences Letters 2018; 6(2): 31-40. ISSN(e): 2312-4318 ISSN(p): 2312-5659. https://doi.org/10.18488/journal.73.2018.62.31.40.

8. PricewaterhouseCoopers International Limited June 2020. PwC's Micro Small and Medium Enterprises Survey 2020: Building to Last Nigeria Report. Retrieved on Friday, 30 April 2021. https://www.pwc.com/ng/en/assets/pdf/pwc-msme-survey-2020-final.pdf.

9. Adenikinju A. Efficiency of the Energy Sector and its Impact on the Competitiveness of the Nigerian Economy. International Association for Energy Economics; 2003.

10. Akinson AO. Effect of infrastructural facilities on SMEs Growth in Nigeria. Int J Innovative Res Dev. 2018; $7(6)$. ISSN 2278 - 0211 (Online). 
11. Olubusoye OE, Akintande OJ, Adenikinju AF, Olanrewaju BT. Modeling the determinants of renewable energy consumption: evidence from the five most populous nations in Africa. J Homepage. 2020. www.elsevier.com/locate/energy.

12. Olatunji $\mathrm{O}$, et al. Electric power crisis in Nigeria: a strategic call for change of focus to renewable sources. IOP Conference Series: Mater Sci Eng. 2018;413: 012053. https://doi.org/10.1088/1757-899X/413/1/012053.

13. Frederick D, Salese AE. The effect of electric power fluctuations on the profitability and competitiveness of SMEs: a study of SMEs within the Accra business district of Ghana. J Competitiveness. 2014; 6(3): 32-48. ISSN 1804-171X (Print), ISSN 1804-1728 (Online), https://doi. org/10.7441/joc.2014.03.03

14. Adeyoyin SO, Alawiye M. Awareness and use of solar energy as alternative power source for ICT facilities in Nigerian University Libraries and Information Centers. Library Philosophy and Practice (ejournal). 2372. https://digitalcommons.unl.edu/libphilprac/2372.

15. Frederick $\mathrm{N}$, Josephine A. Effect of power supply on the performance of small and medium size enterprises: a comparative analysis between SMEs in Tema and the Northern part of Ghana. Paper No. 74196, posted 02 Oct 2016 20:42 UTC. https://mpra.ub.uni-muenc hen.de/74196/MPRA.

16. Yusuf $O A$, Adeyemi OA. Factors influencing willingness to adopt renewable energy technologies among micro and small enterprises in Lagos state Nigeria. Int J Sustain Energy Plan Manag. 2019;19:69-82.

17. Olatunji DO. Electricity insecurity and the performance of small scale businesses in Akoko Area of Ondo State, Nigeria. Int J Business Social Sci. 2019. https://doi.org/10.30845/ijbssv10n7p17.

18. Forkuoh KS, Li Y. Electricity power insecurity and smes growth: a case study of the cold store operators in the asafo market area of the kumasi metro in Ghana. Open J Business Manag. 2015;3:312-25. https://doi.org/10.4236/ojbm.2015.33031.

19. Abubakar S, Olusegun KL. Electricity supply and performance of small and medium enterprises in Nigeria: assessing selected firms in North-Western States. World Journal of Innovative Research. 2019; 6(4): 91-99. ISSN: 2454-8236.

20. Awogbemi O, Oluwaleye IO, et al. a survey of solar energy utilization for sustainable development in Nigeria. J Multidisciplinary Eng Sci Technol (JMEST). 2015; 2(7). ISSN: 3159-0040.

21. Madeleine Broman Toft September 2014. Consumer adoption of sustainable energy technology—the case of smart grid technology. A PhD Thesis Submitted to Business and Social Sciences, Aarhus University.

22. Nnaemeka VE, Kyung-Jin B. Sustainable energy development in Nigeria: overcoming energy poverty. Int J Energy Econ Policy ISSN: 2146-4553. 2015, 5(2), 580-597. http: www.econjournals.com.

23. European Union, German Cooperation (Deutsche Zusammenarbeit) June 2015. The Nigerian Energy Sector an Overview with a Special Emphasis on Renewable Energy, Energy Efficiency and Rural Electrification. 2nd Edition.Authors/Editors: GOPA-International Energy Consultants GmbH Justus-von-Liebig-Str. 1, 61352 Bad Homburg v.d.H. Germany www.gopa-intec.de.

24. Lagos State Government Bureau of Statistics. Digest of Statistics. Ministry of Economic Planning and Budget, The Secretariat, Alausa, Ikeja - Lagos, Nigeria; 2017.

25. Bank of Industry of Nigeria (N/A). Micro, Small and Medium Enterprises Definition. https://www.boi.ng/smedefinition/. Accessed 01 May 2021.

26. Battle J. Binary logistic regression. 2012. https://www.juanbattle.com/files/2012/04/Regression-Logistic-4.pdf. Accessed 18 Apr 2021.

27. National Bureau of Statistics. Micro, Small, and Medium Enterprises (MSME) National Survey 2017 Report. Lagos State, Nigeria. 2019.

28. Small and Medium Enterprises Development Agency of Nigeria. National Policy on Micro, Small and Medium Enterprises. https://www. smedan.gov.ng/images/PDF/MSME-National-Policy.pdf. Accessed 01 May 2021.

Publisher's Note Springer Nature remains neutral with regard to jurisdictional claims in published maps and institutional affiliations. 